\title{
A Educação Ambiental Popular enquanto contributo ao PAIETS
}

\author{
La Educación Ambiental Popular como contribución al PAIETS
}

Popular Environmental Education as a contribution to PAIETS

\author{
Roberta Avila Pereira ${ }^{1}$ \\ Lisiane Costa Claro ${ }^{2}$ \\ Vilmar Alves Pereira ${ }^{3}$
}

\begin{abstract}
Resumo
Consideramos os campos da Educação Ambiental e da Educação Popular como contributos à formação de educadores que tenham como ponto em comum a resistência à lógica opressora. A Educação Ambiental e Popular, portanto, possibilita a base epistemológica para orientar as atividades educativas de extensão no contexto do Programa de Auxílio ao Ingresso nos Ensinos Técnico e Superior (PAIETS), da Universidade Federal do Rio Grande (FURG). A Educação Ambiental e Popular é aqui entendida como um espaço relevante para teorizar as experiências vinculadas ao tornar-se professor (a) e educador (a) - ambiental e popular - . Por esse viés, objetivamos apresentar algumas possibilidades na formação dos educadores, em um horizonte mais integral e humanizador com base na proposta de uma Educação Ambiental, adjetivada pela concepção que assume o termo "Popular". Desse modo questionamos: Como o âmbito da Educação Ambiental e Popular pode contribuir na formação docente e de educadores (as)? Para tanto, realizamos uma abordagem compreensiva de cunho hermenêutico-fenomenológico (PEREIRA, 2016 e RICOEUR, 2014). Consideramos que, para além da contribuição dos saberes da Educação Ambiental e Popular no campo dos fundamentos da educação, esses conhecimentos, instigam a redefinição das bases formativas docentes num horizonte mais humano, crítico, (cri) ativo e transformador
\end{abstract}

Palavras-Chave: PAIETS; Educação Ambiental Popular; Formação de educadores.

\section{Resumen}

Consideramos los campos de la Educación Ambiental y de la Educación Popular como aportaciones a la formación de educadores que tengan como punto en común la resistencia a la lógica opresora. La Educación Ambiental y Popular, por lo tanto, posibilita la base epistemológica para orientar las actividades educativas de extensión en el contexto del Programa de Auxilio al Ingreso en las Enseñanzas Técnico y Superior (PAIETS), de la Universidad Federal del Río Grande (FURG). La Educación Ambiental y Popular es aquí entendida como un espacio relevante para teorizar las experiencias vinculadas al convertirse en profesor (a) y educador (a) ambiental y popular -. Por ese sesgo, objetivamos presentar algunas posibilidades en la formación de los educadores, en un horizonte más integral y humanizador con base en la propuesta de una Educación Ambiental, adjetivada por la concepción que asume el término "Popular". De ese modo cuestionamos: ¿Cómo el ámbito de la Educación Ambiental y Popular puede contribuir en la formación docente y de educadores (as)? Para ello, realizamos un abordaje comprensivo de cuño hermenéutico-fenomenológico (PEREIRA, 2016 y RICOEUR, 2014). Consideramos que, además de la contribución de los saberes de la Educación Ambiental y Popular en el campo de los fundamentos de la educación, esos conocimientos, instigan la redefinición de las bases formativas docentes en un horizonte más humano, crítico, creativo y activo y transformador.

\footnotetext{
1 Mestranda em Educação Ambiental; Programa de Pós-Graduação em Educação Ambiental - PPGEA da Universidade Federal do Rio Grande - FURG; Rio Grande, Rio Grande do Sul, Brasil; robertapereira108@gmail.com.

${ }^{2}$ Doutora em Educação Ambiental; Instituto Federal do Rio Grande do Sul - IFRS; Rio Grande, Rio Grande do Sul, Brasil; lisianecostaclaro@gmail.com.

${ }^{3}$ Doutor em Educação; Universidade Federal do Rio Grande - FURG; Rio Grande, Rio Grande do Sul, Brasil; vilmar1972@gmail.com.
} 
Palabras claves: PAIETS; Educación Ambiental Popular; Formación de educadores.

\begin{abstract}
We consider the fields of Environmental Education and Popular Education as contributions to the formation of educators who have as a common point resistance to oppressive logic. The Environmental and Popular Education, therefore, allows the epistemological basis to guide the extension educational activities in the context of the Federal University of Rio Grande (FURG) Program of Assistance to the Admission to Technical and Higher Education (PAIETS). Environmental and Popular Education is here understood as a relevant space to theorize the experiences linked to becoming a teacher and educator - environmental and popular. From this perspective, we aim to present some possibilities in the formation of educators, in a more integral and humanizing horizon based on the proposal of an Environmental Education, adjectivada by the concept that assumes the term "Popular". In this way we question: How can the scope of Environmental and Popular Education contribute to the formation of teachers and educators? For that, we performed a comprehensive hermeneutic-phenomenological approach (PEREIRA, 2016 and RICOEUR, 2014). We consider that, in addition to the contribution of the knowledge of Environmental and Popular Education in the field of educational foundations, this knowledge instigates the redefinition of the formative teaching bases in a more human, critical, creative and active and transforming horizon.
\end{abstract}

Keywords: PAIETS; Popular Environmental Education; Training of educators.

\title{
1. Introdução
}

Vivenciamos, nesse momento no Brasil, um momento em que a democracia ainda sente os fortes efeitos do Golpe de Estado, de 2015, resultado da união de forças conservadoras com seus reflexos em todo o mundo, que culmina com o recente resultado das eleições brasileiras. Diante disso, compreendemos que as camadas populares são as que mais sofrem por terem encolhidos e negados, cotidianamente, seus direitos. Como desdobramento desse fenômeno, vemos as múltiplas reformas posterior ao golpe que vêm limitando ao filho e à filha do trabalhador (a) as possibilidades de ter acesso as garantias básicas, como a educação pública de qualidade. É fundamental identificarmos que se tratam de práticas reafirmadas em inúmeros discursos já há um bom tempo, sob o efeito das políticas neoliberais que, no caso brasileiro, se enraizaram em todos os campos.

Mediante esse cenário de incerteza e de diminuição de direitos, de reforço da lógica individualista, necessitamos de projetos e ações coletivas voltadas para luta e defesa dos direitos básicos, sendo a principal delas o acesso à educação. É nesse horizonte que buscamos apresentar as contribuições da Educação Ambiental Popular para as ações realizadas junto ao PAIETS; compreendendo o Programa enquanto um espaço de resistências, lutas, sonhos e buscas de realizações ontológicas no sentido do "ser mais".

Desse modo questionamos como a Educação Ambiental Popular pode contribuir na formação docente e de educadores (as) no PAIETS. Para isso, realizamos uma abordagem compreensiva de cunho hermenêutico-fenomenológico (PEREIRA, 2016 e RICOEUR, 2014). 
Essa abordagem possibilita uma leitura sobre as atividades do Programa, seus fundamentos, princípios e objetivos, assim como viabiliza o entendimento sobre as possibilidades que o PAIETS assume ao subsidiar-se na Educação Ambiental Popular como base possível para uma formação de educadores engajados no horizonte de um projeto de sociedade justo e compromissado com as várias formas de vida na e da Terra.

A seguir, apresentaremos o Programa de Extensão: sua trajetória, seus espaços de atuação, os desafios e as demandas existentes nessa história. Além disso, destacaremos as bases teóricas que contribuem para a elaboração das práticas educativas e pedagógicas que orientam as ações do programa, enfatizando como possibilidade a contribuição da Educação Ambiental Popular.

\section{PAIETS: contextualizando o Programa}

A experiência germinal do PAIETS emerge da organização de cursos préuniversitários populares na cidade do Rio Grande/RS no ano de 2000 com o curso préuniversitário popular "Sem Limites", que mais tarde passou a chamar-se de "Utopia". Este curso acontecia nas dependências do Hospital Universitário e teve início com a organização autônoma de estudantes vinculados ao movimento estudantil da Universidade Federal do Rio Grande. Com o passar dos anos, novas experiências são criadas em diferentes comunidades urbanas periféricas da cidade. Esses cursos, tinham como ponto de confluência a busca pelo acesso das camadas populares ao ensino superior.

No ano de 2006, um projeto de extensão que procurava articular essas iniciativas foi um marco na organização dessas experiências sendo uma conquista importante que serviria de base para o fortalecimento da luta pelo ingresso na Universidade. A partir do ano de 2007 é aprovado o Programa de Auxílio ao Ingresso nos Ensinos Técnico e Superior no âmbito da Universidade Federal do Rio Grande - FURG, enquanto um Programa de Extensão contemplado no edital PROEXT 06/2007, visando contribuir na criação e manutenção dos diversos cursos voltados à luta de ingresso da comunidade popular ao ensino técnico e superior públicos.

O PAIETS buscava congregar estas experiências no horizonte da Educação Popular, objetivando a partilha dos êxitos e dos desafios presentes nos distintos contextos. Sobretudo, a proposta tinha como intuito fortalecer as experiências na luta pela democratização do ensino superior público. O PAIETS desde sua gênese buscou manter e respeitar a autonomia de cada um dos cursos os quais funcionavam em parceria com a comunidade geral. 
As vivências que emergem neste percurso do Programa, são indispensáveis para a compreensão do alcance que o trabalho coletivo junto à comunidade. Para além da colocação do mesmo enquanto $1^{\circ}$ lugar (junto a outros 2 projetos) em âmbito nacional com referência a relevância das atividades em extensão, o PAIETS identifica sua consolidação e pertinência na luta por uma universidade mais justa e democrática, bem como na construção de uma sociedade mais humana e igualitária, ao reconhecer as histórias de vida dos sujeitos que contribuem para sua (re)existência.

O PAIETS atua em cinco frentes: 1) No acesso ao Ensino Superior junto aos PréUniversitários Populares, Pré-IF e ao curso de acesso à Pós-Graduação. 2) Na retomada à educação básica junto a Jovens e Adultos (das comunidades tradicionais de pesca artesanal e da comunidade LGBT, nas quais o PAIETS atua como parceiro de organização). 3) $\mathrm{Na}$ permanência de sujeitos oriundos de comunidades quilombolas e indígenas no espaço acadêmico. 4) Na formação docente da rede pública junto a EJA. 5) No diálogo intercultural junto aos imigrantes senegaleses em Rio Grande/RS.

Sobre a primeira frente de atuação destacada, o PAIETS agrupa cursos PréUniversitários Populares, configurando-se enquanto um movimento articulador entre as comunidades urbanas periféricas e periurbanas, que busca contribuir com o direito do ingresso das camadas populares nos espaços educativos os quais foram historicamente destinados às camadas mais abastadas. Nesse processo de luta pelo acesso à Universidade, acadêmicos de graduação, pós-graduação, além de docentes e colaboradores graduados, desenvolvem práticas educativas de diferentes áreas do conhecimento que auxiliam no preparo ao ENEM, aos processos seletivos dos Institutos Federais e também na formação para o acesso à Pós-Graduação.

Encontram-se vinculados ao programa 07 cursos Pré-Universitários Populares no município do Rio Grande/RS, que estão em desenvolvimento nas vilas e bairros populares da cidade. São eles: Paideia; Maxximus; Fênix; Acreditar; Quinta Superação; Esperança e Povo Novo. Além disto, 01 curso Pré-Universitário Popular em São José do Norte/RS, Ousadia Popular; 01 curso Pré-Universitário Popular em Capão do Leão/RS, Curso Up e 01 curso PréUniversitário Popular em Santo Antônio da Patrulha/RS, Super Ação Comunitária (Saci).

Com relação à reivindicação pela permanência dos sujeitos oriundos das comunidades tradicionais indígenas e quilombolas no espaço acadêmico, a atividade ocorre desde 2012, em coerência com a Lei $n^{\circ}$ 12.711/2012, que trata da Política de Cotas. O PAIETS Indígena e Quilombola surge com sua atuação voltada ao acolhimento e a permanência de estudantes indígenas e quilombolas, que ingressam na Universidade por meio de processo seletivo 
específico. Esses encontros emergem a partir da demanda em relação aos desafios enfrentados pelos educandos ao adentrar a Universidade, trabalhando a partir das suas necessidades, para uma melhoria no seu desempenho enquanto graduando. Neste sentido, as práticas do Programa visam realizar um acompanhamento desses estudantes por meio de oficinas e encontros formativos que preconizem não apenas o suporte conteudinal para as disciplinas e componentes curriculares presentes nos cursos superiores, mas que, também buscam fortalecer as relações de identidade e partilhar os desafios e produções de conhecimento e saberes no espaço acadêmico.

A respeito da retomada do acesso ao ensino básico, o PAIETS também promove como parceiro do Projeto Educação para Pescadores, práticas pedagógicas e formação escolar em zonas periubanas e rurais com o Ensino de Jovens e Adultos de comunidades de pesca artesanal. Por meio de uma educação problematizadora e compromissada com o poder popular, turmas de ensino médio, fundamental em lugares da região sul (Ilha Torotama, Ilha dos Marinheiros e Capilha, na localidade do Taim) já foram formadas.

Outra frente de atuação é a parceria que o Programa realiza junto ao projeto Manas na Escola, direcionado a demanda da comunidade (LGBT), busca um espaço de compartilhamento de saberes com o foco em travestis e transexuais do gênero feminino (mas que também vem acolhendo mulheres cisgênero), tendo em vista a grande evasão da escola devido às dificuldades e preconceitos sofridos por essa parcela da sociedade. A inclusão e a diversidade são potencializadas nesses espaços educativos e se estende para a formação docente como vemos a seguir.

O PAIETS atua junto ao Curso Educação de Jovens e Adultos na Diversidade e Inclusão Social, oferta de formação em nível de aperfeiçoamento, no espaço de formação permanente com educadores da EJA, da rede pública municipal e estadual de Rio Grande, São Lourenço do Sul e Capão do Leão. Trata-se de um curso voltado à formação continuada de educadores da Educação de Jovens e Adultos - EJA, onde são realizados mensalmente encontros em círculos de cultura. A metodologia que orienta os encontros com os educadores vinculados ao projeto, divididos em pequenos grupos, é a compreensão que a prática educativa precisa ser repensada e ressignificada através do local onde "os pés pisam".

Já na quinta frente de atuação do programa, temos o PAIETS Imigrantes: diálogos interculturais que busca uma estabelecer um diálogo com os imigrantes senegaleses em Rio Grande/RS. Através do reconhecimento da presença destes imigrantes no município, objetiva-se, além de (re)conhecer esta cultura, possibilidades de aprendizagens outras, através da escutatória freireana. Neste sentido, nesta frente de luta do programa, (re)afirmamos que a 
importância destes imigrantes e suas dimensões de vida enquanto uma cultura que tem muito a nos ensinar e compartilhar.

Assim, nas cinco instâncias evidenciadas, almeja-se a democratização dos espaços formativos institucionalizados por meio de uma postura crítica e emancipadora. Por meio da Educação Popular, o PAIETS auxilia na responsabilidade social assumida pela FURG com a comunidade.

O PAIETS tem na extensão universitária a possibilidade de reivindicar não só uma academia mais democrática e popular, como um mundo mais igualitário. Contudo, a caminhada só é possível junto aos sujeitos que atuam no horizonte da superação dos limites impostos frente ao modelo hegemônico. Estes protagonistas partem da comunidade geral que acolhe os contextos de atuação do Programa, as escolas públicas que sediam os cursos, os educandos que acreditam no trabalho realizado e que participam da construção destes espaços, os educadores populares que não carregam um frágil sentido de voluntarismo, mas compreendem-se enquanto indivíduos dispostos a aprender com o outro na luta pela defesa à educação de todas as pessoas.

Compreendemos que a entrada das camadas populares na Universidade representa a ampliação da luta pela justiça social. Os contextos trabalham em favor da luta dos oprimidos; sendo a formação humana presente em cada contexto, o diferencial que nutre as expectativas de um projeto de sociedade menos desigual. É possível afirmar que a maioria dos egressos do Programa são indivíduos conscientes de sua responsabilidade social no contraponto à lógica opressora. Lideranças, representantes de movimentos sociais estudantis e demais movimentos populares, profissionais comprometidos com os aspectos da comunidade, são sujeitos que se formam nos contextos do PAIETS. Assim, é preciso destacar que o Programa é nutrido pelos sonhos dos inconformados com as desigualdades e com as opressões, que ao buscarem uma sociedade mais justa por meio da garantia dos direitos conquistados pelo povo, acreditam e trabalho em favor da humanização e transformação social.

\section{Horizontes epistemológicos do PAIETS}

Considera-se que a Educação Ambiental é um campo disputado por diferentes possibilidades de se fazer e teorizar a pauta ecológica. Por isso, demarcarmos uma possibilidade por meio da compreensão da "Educação Ambiental Popular". O termo surge no México em 1987, quando da criação de uma Rede que buscava um espaço dialógico entre educadores populares que recorriam a elaboração de uma outra racionalidade, de cunho ambiental (PERALTA, 1997). Segundo Barbosa (2002), essa proposta configurou-se por 
meio da Red de Educación Popular y Ecologia - REPEC, que surgiu como proposta de membros vinculados ao Consejo de Educación de Adultos de America Latina-CEAAL.

Retomar esses movimentos que organizam o escopo dos estudos no horizonte da Educação Ambiental e Popular, trata-se de um exercício necessário que buscamos potencializar, de maneira em que esta retomada, junto as práticas articuladas à extensão e ao ensino, promovem uma formação de educadores (as) ambientais e populares compromissados com a própria prática.

A partir desta perspectiva e dos princípios da Educação Ambiental Popular, considerase a postura hermenêutica fenomenológica, na medida em que ela se apresenta enquanto um horizonte de compreensão que permite a emergência do diálogo entre os sujeitos, suas vivências, leituras de mundo e experiencias vividas, partindo de um viés de encontro com o outro, com o mundo e consigo mesmo. Neste sentido, a hermenêutica postula a busca de compreensões do sujeito no mundo e com o mundo.

Concordamos que o viés compreensivo se traduz como a "outridade do pensamento científico" (PEREIRA, 2016), portanto, reivindicando outras possibilidades de produção do conhecimento no âmbito da pesquisa. Além disso, consideramos a Hermenêutica pois busca compreender o mundo como texto a ser lido e a conduta Fenomenológica pois, de inspiração ricoueriana, realiza o exercício de afastamento e reaproximação no que se refere às possibilidades e processos de entendimento - inclusive do "si-mesmo", pensando no "sujeito pesquisador" (RICOUEUR, 2014).

Compreende-se que a educação, no que se refere ao pensamento ocidental, foi marcada pelo pensamento dualista. Este processo é percebido desde a Antiguidade ${ }^{4}$, passando pelo medievo com a expressão nas obras de Agostinho e Tomás de Aquino - os quais retornam a essa concepção de perfeição versus imperfeição ${ }^{5}$ - e reforçado na modernidade (com o advento da ciência enquanto legitimadora de determinada sociedade antropocêntrica, desprezando outros saberes). Assim:

\footnotetext{
$\mathrm{Na}$ sociedade ocidental, veremos que subjacentemente às relações sociais instituídas em meio a tensões, conflitos e lutas, elabora-se um conceito determinado de natureza que fundamentalmente dela desloca o homem. E aí se torna fácil perceber por que o imaginário ocidental costumeiramente associa à natureza os segmentos ou classes sociais oprimidos e explorados, naturalizando essas condições (PORTOGONÇALVES, 2011, p.125)
}

\footnotetext{
${ }^{4}$ Isto com a influência do pensamento de Platão, o qual evidenciava o mundo das ideias enquanto o plano ideal em contraposição ao mundo imperfeito que habitamos.

${ }^{5}$ Este pensamento vinculado à religião e, portanto, articulado à noção de pecado.
} 
Nesse prisma, ao identificar a dualidade na própria constituição dos sentidos de "natureza" destaca-se um exemplo do quanto é pertinente a aproximação dessas duas áreas: acredita-se que a Educação Ambiental, ao problematizar os sentidos de natureza em diálogo com a Educação Popular, contribui de forma a instigar a problematização sobre o papel do ser humano como partícipe da natureza. Conexões como essa, ao voltarem-se para os desafios e anseios das camadas populares, acarretariam no (re)pensar e (re)fazer as responsabilidades individuais e coletivas em torno das comunidades populares.

Nesse horizonte, compreende-se a proximidade com o desafio de conceber a postura ambiental a qual apresenta sua fragilidade de compreensão ao pensá-la na modernidade. Grün (1996) coloca que a questão ambiental, assume uma dimensão pertinente na formação dos sujeitos, especialmente se reconhecida enquanto um espaço silenciado da educação moderna. Neste viés, de forma a buscar romper com a visão superficial, que não problematiza o ambiente e as decorrências de seu inócuo entendimento, a

\section{[...]educação ambiental em construção em um movimento contra-hegemônico é a crítica ao paradigma cientificista-mecanicista que informa a sociedade moderna urbano-industrial; crítica ao seu modelo de desenvolvimento, ao seu modo de produção, com suas múltiplas determinações da realidade social, que se concretiza na proposta de uma modernização que é conservadora - porque muda (moderniza) para manter a situação atual (status quo) - e que promove, ainda, de acordo com sua racionalidade, o direcionamento para uma compreensão única de mundo (GUIMARÃES, p. 46, 2013).}

Logo, defende-se que a Educação Ambiental Popular, aposta em outras maneiras de educar pois contempla a conduta histórica; haja vista que busca fazer com que as visões ecológicas de mundo sejam postas em debate, entendidas, interrogadas e incorporadas na sociedade, bem como nas manifestações culturais. Desse modo, acredita-se na Educação Ambiental Popular enquanto concepção que acolhe outras formas de ser e estar no mundo na busca pela construção de fundamentos capazes de contribuir com a pauta ambiental.

Considera-se que a proposta ganha viabilidade ao reconhecer que a Educação Ambiental Popular vai além de um instrumento de mudança cultural ou comportamental, mas representa uma reivindicação de rever os fundamentos neste campo educativo, de maneira a superar as concepções dicotômicas (como "Humanidade/Natureza"; "Teoria/Prática", "Saber/Conhecimento").

Deste modo, a Educação Ambiental Popular é um espaço educativo onde coexistem subjetividades diversas, abarcando diferentes saberes, de maneira a assumir o diálogo enquanto experiência coletiva num viés solidário. Esta dinâmica faz emergir um 
conhecimento novo a partir destas relações tramadas na pluralidade. Por isso, identifica-se enquanto princípio as redes tramadas na coletividade, solidariedade e no diálogo.

Para além da superação das dicotomias, busca-se no horizonte da Educação Ambiental e Popular, superar os processos de dominação dos homens entre si e da humanidade à natureza. Por isso, uma proposta que busca contrapor a prática comum das classes dominantes, assim como a banalização de certas questões que acarretam em opressão e desrespeito às idiossincrasias do ser humano.

Neste rumo, a Educação Ambiental Popular tem seu alicerce a compreensão da relação entre conhecimento e poder, reconhecendo e valorizando os saberes diversos da racionalidade científica, contrapondo-se a polarização entre teoria e prática. Enquanto uma concepção de educação processual, este horizonte se compromete com a construção de um processo de transformação social e de exercício da cidadania, a partir da ação local na resolução de problemas da comunidade, compreendendo a transformação global a partir da ação cotidiana, numa metodologia comprometida com a prática da participação direta e na autocompreensão de que a educação é sempre política (BARBOSA, 2002).

Freire (1999) afirma que a partir dos saberes da vida dos sujeitos, é que se desenvolvem práticas emancipatórias e coletivas, isso significa propor um novo olhar sobre questões que estão no âmbito educativo. Assim, a Educação Ambiental com predicado Popular compreende intencionalidade emancipatória. Esta emancipação ocorre por meio do diálogo que conduz os sujeitos à visão crítica acerca das relações sociais de produção que perpetuam discursos e práticas. Isto significa propor um novo olhar sobre o processo de construção de conhecimento, que aponta para uma nova ontologia, onde a concepção de totalidade de ambiente, pluralismo de ideias e a integralidade do mundo da vida esteja no cerne.

\section{Considerações finais}

A partir do olhar compreensivo realizado no PAIETS, identificamos que os desdobramentos do pensamento dicotômico estão presentes nos entendimentos acerca do campo do conhecimento e de Ciência. Portanto, consideramos que a formação docente no Programa, é um campo que se abre para a reivindicação de novas abordagens e problematização acerca dos fundamentos de cunho mais tradicional, rumo às outras possibilidades de elaboração do conhecimento. Apostamos que os saberes da Educação Ambiental e Popular, representam um caminho viável a esta articulação. 
É imprescindível ressaltar que o PAIETS demarca a luta pela superação dos valores presentes em uma sociedade opressora. Neste sentido, acreditamos que as práticas realizadas a partir da concepção da Educação Ambiental Popular contribuem para a elaboração de uma sociedade mais justa e solidária, a qual compartilhe um projeto educativo pautado na coletividade e nos valores para a vida humana.

A Educação Ambiental Popular contribui para uma conduta menos dual no horizonte da educação integral; pois instiga a crítica acerca das segregações que alimentam a lógica opressora. Pensar o ambiente, a natureza, a humanidade e as sociedades é construir uma nova conduta e no horizonte das compreensões, presente na postura hermenêutica, essa distinção entre teoria e prática são inconcebíveis.

\section{Referências}

BARBOSA, Malba Tahan. Educação Ambiental Popular: A experiência do centro de vivência Agroecológica CEVAE/TAQUARIL. 2002.

Grün, M. Ética e educação ambiental: uma conexão necessária. Campinas:

Papirus, 1996.

FREIRE, Paulo. Educação como prática da liberdade. 23 a ed. Rio de Janeiro: Paz e Terra, 1999.

PERALTA, Joaquín Esteva. Ambientalismo y educación. Hacia una educación popular ambiental en América Latina. Congreso Iberoamericano de Educación Ambiental. Guadalajara, 1992.

RICOEUR, P. O Si-Mesmo como Outro. Tradução: Inove C. Benedetti. $1^{\text {a }}$ ed. São Paulo: Editora WMF Martins Fontes, 2014

PEREIRA, V.A. Hermenêutica e Educação Ambiental no contexto do pensamento pósmetafísico. $1^{\text {a }}$ ed. Juiz de Fora, MG: Garcia edizioni, 2016.

PORTO-GONÇALVES, Carlos Walter. Os (Des)caminhos do Meio Ambiente. 15a . ed. Sãio Paulo: Contexto, 2011. 